\title{
PET/CT in the Evaluation of Hypoxia for Radiotherapy Planning in Head and Neck Tumors: Systematic Literature Review
}

\author{
Susana Lopes ${ }^{1}$, Sara Ferreira ${ }^{2}$, and Marco Caetano ${ }^{3}$ \\ ${ }^{I}$ Nottingham University Hospitals, Nottingham, United Kingdom; ${ }^{2}$ Dr. Lopes Dias School of Health-Polytechnic Institute of Castelo \\ Branco, Castelo Branco, Portugal; and ${ }^{3}$ Lisbon School of Health Technology-Polytechnic Institute of Lisbon, Lisbon, Portugal
}

CE credit: For CE credit, you can access the test for this article, as well as additional JNMT CE tests, online at https://www.snmmilearningcenter.org. Complete the test online no later than June 2024. Your online test will be scored immediately. You may make 3 attempts to pass the test and must answer $80 \%$ of the questions correctly to receive $1.0 \mathrm{CEH}$ (Continuing Education Hour) credit. SNMMI members will have their CEH credit added to their VOICE transcript automatically; nonmembers will be able to print out a CE certificate upon successfully completing the test. The online test is free to SNMMI members; nonmembers must pay $\$ 15.00$ by credit card when logging onto the website to take the test.

PET/CT combines imaging at the molecular level along with imaging at the anatomic level, which, with the administration of a hypoxia-sensitive radiopharmaceutical, allows evaluation of tissue oxygenation. Methods: This work consisted of a systematic literature review that included websites, books, and articles dated from July 1997 to December 2019. The aim was to identify the PET radiopharmaceuticals best suited to the detection of cell hypoxia and to recognize the benefits for planning intensity-modulated radiation therapy (IMRT) and volumetric arc therapy (VMAT). Results: Hypoxia affects the likelihood of cure for head and neck tumors, reducing the success rate. Radiopharmaceuticals such as ${ }^{18} \mathrm{~F}$ fluoromisonidazole, ${ }^{18} \mathrm{~F}$-fluoroerythronitromidazole, and ${ }^{18} \mathrm{~F}-\mathrm{HX} 4$ (18F-3-fluoro-2-(4-((2-nitro-1H-imidazol-1-yl)methyl)-1H-1,2,3triazol-1-yl)propan-1-ol) allow the delineation of hypoxic subvolumes within the target volume to optimize IMRTNMAT. Conclusion: Identification of hypoxic areas with PET/CT imaging and use of subsequent IMRTNMAT allows for possible escalation of radiation dose in radioresistant subvolumes, with a consequent decrease in relapses and an increased likelihood of disease-free survival.

Key Words: hypoxic cells; PET/CT; head and neck tumors; treatment planning; radiotherapy

J Nucl Med Technol 2021; 49:107-113

DOI: 10.2967/jnmt.120.249540

\section{$\mathbf{P}$} ET/CT, as a hybrid imaging technique, plays an important role in radiotherapy planning $(1,2)$, allowing the identification of metabolism, cell proliferation, and hypoxia allied to the anatomy (1,3-5). After PET/CT images have been obtained for radiotherapy planning and subsequent identification

\footnotetext{
Received Jun. 8, 2020; revision accepted Nov. 9, 2020.

For correspondence or reprints contact: Susana Lopes, Nottingham University Hospitals, Hucknall Rd., Nottingham NG5 1PB, U.K.

E-mail: lopesusana686@gmail.com

Published online Dec. 24, 2020.

COPYRIGHT (c) 2021 by the Society of Nuclear Medicine and Molecular Imaging.
}

of hypoxic areas, intensity-modulated radiation therapy (IMRT) and volumetric arc therapy (VMAT) can be used, 2 conformal treatment techniques that allow modulation of the radiation deposited according to oxygenation levels, decreasing the likelihood of toxicity in adjacent healthy tissues (6-10).

In head and neck tumors, which include the paranasal sinuses, oral and nasal cavity, salivary glands, tongue, larynx, and pharynx, the application of this imaging technique for radiotherapy planning using specific radiotracers allows precise definition of the hypoxic areas and, consequently, a more individualized treatment (11-13).

In Portugal in 2010, head and neck tumors were more common in men than women. Of all head and neck tumors, those of the larynx demonstrated the highest incidence and mortality rates and were considered the ninth most common tumor in men. In addition to the larynx, tumors in the tongue and oral cavity also have a high incidence and mortality rates (Table 1) (14). Given the low survival rate in head and neck cancers, there is a need to invest in appropriate therapy; to this end, technologic developments have enabled optimization of the planning and treatment technique. Identification of tumor hypoxia is essential, as it is a poor prognostic factor given the radioresistance of hypoxic cells $(8,15-17)$. Therefore, PET/CT for radiotherapy planning, taking into account the evaluation of hypoxia, seems a viable option.

\section{MATERIALS AND METHODS}

This work was a systematic review of the literature on PET/CT imaging demonstrating hypoxia, head and neck tumor treatment planning with PET/CT, and treatment of head and neck tumors with IMRT/VMAT. Sixty-eight references were included (Fig. 1), namely websites, articles, and books, searched in the PubMed, bon (Biblioteca do Conhecimento Online), Google, and Google Scholar databases in Portuguese and English, dated from July 1997 to December 2019. The following Boolean logic was used to search for information: radiotherapy planning treatment AND 
TABLE 1

Incidence and Mortality Rate of Head and Neck Tumors (14)

\begin{tabular}{lcc}
\hline $\begin{array}{c}\text { Tumor } \\
\text { location }\end{array}$ & $\begin{array}{c}\text { Incidence } \\
\text { per } 100,000\end{array}$ & $\begin{array}{c}\text { Mortality } \\
\text { per 100,000 }\end{array}$ \\
\hline Lip & 2 & 0.1 \\
\hline Tongue & 3 & 1.3 \\
\hline Oral cavity & 3.1 & 1.3 \\
Salivary glands & 1 & 0.5 \\
Amygdala & 1.3 & 0.4 \\
Oropharynx, other & 1.2 & 1 \\
Nasopharynx & 0.9 & 0.5 \\
Hypopharynx & 2.1 & 0.9 \\
Pharynx, other & 0.4 & 0.6 \\
\hline Larynx & 5.9 & 3.7 \\
\hline
\end{tabular}

hypoxia, hypoxic cells AND radiotherapy treatment AND PET, PET/CT AND hypoxia cells AND treatment, PET/CT AND hypoxia cells AND radiotherapy, PET/CT AND cancer AND hypoxia cells, planning with PET/CT and hypoxia, and radiotherapy and treatment planning.

This work aimed to answer the following questions: how does tumor cell oxygen influence treatment; does the entire target volume need the same radiation dose; how important is PET/CT in evaluating hypoxia for treatment planning of head and neck tumors; what radiopharmaceuticals should be used, and why; and can the radiation dose to the organs at risk be reduced in IMRT/VMAT by performing PET/CT planning with hypoxia-sensitive radiotracers?

This article aims to contribute to knowledge about, and the applicability of, PET/CT in the evaluation of hypoxia and to determine the usefulness and contribution of PET/CT to the planning of IMRT/ VMAT techniques for patients with head and neck tumors. Another objective is to describe which radiopharmaceuticals are most indicated for the detection of cell hypoxia.

Some hypotheses are also suggested in this article: that cell hypoxia correlates with a higher likelihood of relapse; that diseasefree survival at $5 \mathrm{y}$ in cases of head and neck tumors and hypoxia may be related; that there is a relationship between PET/CT tracers for hypoxia evaluation and the choice of IMRT/VMAT; and that there is a relationship between the dose deposited in radiotherapy and the selected planning technique.

\section{RESULTS}

\section{PET/CT and Hypoxia in the Tumor}

PET allows the evaluation of molecular pathways, metabolism, proliferation, oxygen uptake, and receptor and gene expression. Molecular imaging is increasingly used for dosimetric planning of volumes of interest and for investigating heterogeneity within these volumes $(2-4,18)$. The hybrid technique, PET/CT, provides tools to the physician for a more accurate diagnosis $(1,5)$. PET/CT in radiotherapy planning allows, precisely, the inclusion of macroscopic and microscopic disease, and with the administration of a specific radiopharmaceutical, it is possible to detect major and minor areas of hypoxia $(3,19)$.

In healthy tissues, oxygen levels are greater than $24 \mathrm{~mm}$ $\mathrm{Hg}$ and may be up to $66 \mathrm{~mm} \mathrm{Hg}$. Hypoxia is characterized by a reduced oxygen rate in cells, which is characterized by being less than $10 \mathrm{~mm} \mathrm{Hg}$, and tumors have zones of high hypoxia (20-26). Hypoxia can be broadly classified as acute or chronic $(6,21,26,27)$. Acute or cyclic hypoxia is caused by a temporary interruption of blood flow and oxygen $(6,24$, $25,27)$. On the other hand, chronic hypoxia results from an increased distance from the tumor to microvessels or from anemia, reducing the amount of oxygen available in the bloodstream $(22,24,26,28,29)$. Chronic hypoxia is stable whereas acute hypoxia is unstable - that is, it changes over time $(21,24,25)$.

The presence of hypoxia in a tumor is a poor prognostic factor, being associated with greater aggressiveness since there is a greater likelihood of metastatic spread and greater resistance to radiotherapy. In radiotherapy of deep tumors, $\mathrm{X}$-ray radiation is used. In molecular terms, the radiation will interact with the biologic tissue through an indirect effect that is superior to the direct effect (2-3 times higher), in which the primary photon reacts with the cellular water, which in its molecular structure contains oxygen. As a result of this interaction, free radicals are produced, damaging the DNA of the target cells. Thus, the reduced oxygen rate affects the curability of tumors, as in cases of head and neck tumors $(19,21,22,24,28,30-34)$.

Authors such as Hendrickson et al. (8), Chang et al. (35), and the International Atomic Energy Agency (32) argue that for the same biologic effect, the total dose of $\mathrm{x}$-irradiation in radiotherapy should be up to 3 times higher in hypoxic cells.

\section{Radiopharmaceuticals for the Detection of Hypoxic Tumor Cells}

The radiopharmaceuticals studied for the evaluation of hypoxia in PET/CT are labeled with ${ }^{18} \mathrm{~F},{ }^{64} \mathrm{Cu}$, or ${ }^{62} \mathrm{Cu}$. Cyclotron-produced ${ }^{18} \mathrm{~F}$ has a physical half-life of $110 \mathrm{~min}$ and decays by $\beta^{+}$emission (97\%), with an energy of 635 $\mathrm{keV}$ and an average soft-tissue range of $0.6 \mathrm{~mm}(9,20,35-$ 37). ${ }^{64} \mathrm{Cu}$ is a radionuclide whose physical half-life is $12.7 \mathrm{~h}$ and decays by $\beta^{+}$emission (17.8\%), with a maximum energy of $0.655 \mathrm{MeV}$ and an average soft-tissue range of $1.4 \mathrm{~mm}(20,38,39) .{ }^{62} \mathrm{Cu}$ is a radionuclide with a half-life of $9.7 \mathrm{~min}$ and decays by $\beta^{+}$emission (97.5\%) (40-44).

PET/CT allows the definition of treatment volumes such as gross tumor volume and biologic tumor volume. A specific hypoxia-detecting radiotracer allows the delineation of hypoxic subvolumes within the tumor volume, a capability that is important for enhancing IMRT/VMAT $(9,10,18,44)$.

In 1981, the radiopharmaceutical studied for detection of hypoxic cells was ${ }^{14} \mathrm{C}$-misonidazole. Two classes of tracer were later studied, one of which was nitroimidazole analogs labeled with ${ }^{18} \mathrm{~F}$. These compounds passively diffuse into the cells. After reduction by nitroreductases in the case of hypoxic cells, there is an accumulation of radicals within the cell. To this class belong ${ }^{18} \mathrm{~F}$-fluoromisonidazole ( ${ }^{18} \mathrm{~F}$-FMISO), ${ }^{18} \mathrm{~F}$-fluoroazomycin arabinoside ( ${ }^{18} \mathrm{~F}$-FAZA), 2-(2-nitro-1H-imidazol-1-yl)- $N$ (2,2,3,3,3- ${ }^{18}$ F-pentafluoropropyl)-acetamide $\left({ }^{18} \mathrm{~F}-\mathrm{EF} 5\right),{ }^{18} \mathrm{~F}$-fluoroerythronitromidazole ( $\left.{ }^{18} \mathrm{~F}-\mathrm{FETNIM}\right),{ }^{18} \mathrm{~F}-(1-(2-1-(1 \mathrm{H}-\mathrm{methyl})$ ethoxy)-methyl-2-nitroimidazole ( $\left.{ }^{18} \mathrm{~F}-\mathrm{RP}-170\right)$, and 


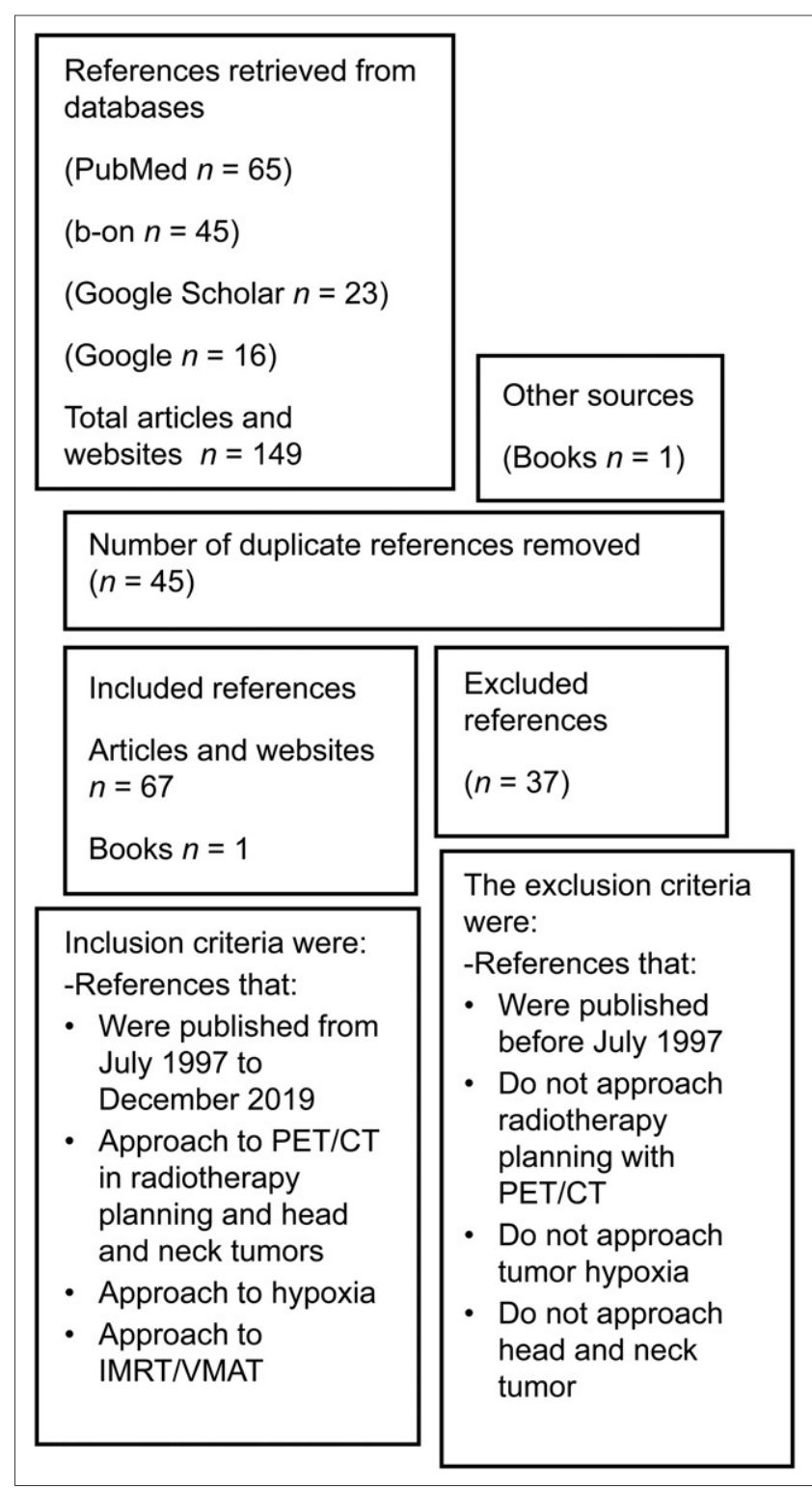

FIGURE 1. Flowchart of inclusion and exclusion of bibliographic references.

${ }^{18}$ F-3-fluoro-2-(4-((2-nitro-1H-imidazol-1-yl)methyl)-1H-1,2,3triazol-1-yl)propan-1-ol ( $\left.{ }^{18} \mathrm{~F}-\mathrm{HX} 4\right)$. Another class of radiopharmaceutical is copper-labeled diacetyl-bis, a class to which belong ${ }^{64} \mathrm{Cu}$-diacetyl-bis $\left(\mathrm{N}^{4}\right.$-methylthiosemicarbazone) $\left({ }^{64} \mathrm{Cu}-\mathrm{ATSM}\right)$ and ${ }^{62} \mathrm{Cu}-\mathrm{ATSM}(20,23,24,29,40-43,45)$.

For imaging acquisitions, the ideal radiopharmaceutical should have a physical and biologic half-life that allow it to decay quickly enough to not increase dosimetry for the patient but slowly enough to allow image formation (46).

For correct visualization of the hypoxic areas of the tumor, it is important that, regardless of the cell type, retention occurs in the hypoxic cells and not in oxygenated or necrotic cells. To achieve this goal, the radiopharmaceutical should be sufficiently lipophilic to have high cellular uptake and rapid equilibrium, or it should be hydrophilic and have faster clearance kinetics, resulting in better contrast between hypoxia and normoxia. Hypoxic variations should not interfere with radiopharmaceutical pharmacokinetics and distribution. The radiopharmaceutical activity to be administered for imaging should be relatively low but adequate to allow imaging. The radiopharmaceutical must be reproducible, easily produced, and highly available $(24,29,38)$. Moreover, an ideal radiopharmaceutical cannot be toxic to humans (46).

Tumor-to-blood and tumor-to-muscle ratios that represent good target-to-background ratios are vital in delimiting target volumes. Nehmeh et al. (47) chose to use a tumor-toblood ratio of greater than 1.2 for volume definition.

Because of the chemical properties of radiopharmaceuticals, each tumor location has its own most appropriate radiopharmaceutical (29).

${ }^{18}$ F-FMISO. In 1986 appeared the radiopharmaceutical ${ }^{18}$ F-FMISO, being currently one of the most widely used radiopharmaceuticals, mainly for head and neck tumors $(20,23,29,35,44,48,49) .{ }^{18} \mathrm{~F}-\mathrm{FMISO}$ is also indicated for lung and prostate tumors (44). Other authors also refer to its utility for gliomas, renal tumors, and breast tumors $(24,29)$.

${ }^{18} \mathrm{~F}-\mathrm{FMISO}$ is lipophilic, ranging in $\log \mathrm{P}$ between -0.42 and -0.38 . This radiopharmaceutical contains 2-nitroimidazole $(20,23,24,29,34,45,50)$ and is eliminated via the hepatobiliary and gastrointestinal tracts (50).

PET using ${ }^{18} \mathrm{~F}$-FMISO has some limitations, such as a short biologic half-life, which has resulted in failure to detect hypoxia and, consequently, a higher risk of failure in locoregional localization, a low tumor-to-background contrast, and low clearance from healthy tissues $(24,29,49,51)$. In addition, ${ }^{18} \mathrm{~F}$-FMISO has no specific retention and is characterized by very slow uptake, which implies a longer residence time in the patient and late imaging $(23,50)$.

Regarding the activity to be administered, authors such as Lee et al. (9), Chang et al. (35), and Hendrickson et al. (8) report an administration of between $3.7 \times 10^{8}$ and $7.4 \times 10^{8} \mathrm{~Bq}$.

Image acquisition, according to Lee et al. (9), Chang et al. (35), and Hendrickson et al. (8), should be performed 2-2.5 h after radiopharmaceutical administration. However, according to Lapa et al. (23), the most acceptable time from administration to image acquisition is about $4 \mathrm{~h}$. According to the Choi et al. (51) and Lopci et al. (20), images should be acquired 2-4 h after an injection, with the acquisition lasting for $10 \mathrm{~min}$.

Lin et al. (52) also suggested acquiring more than one PET/ CT image obtained at different times to verify the efficacy and reproducibility of the radiopharmaceutical for the detection of hypoxia cells. First, a PET scan using a radiopharmaceutical such as ${ }^{18} \mathrm{~F}$-FMISO, which is sensitive to hypoxia, should be acquired. Three days after the start of radiotherapy, another PET/CT image with the same radiopharmaceutical should be acquired (52).

${ }^{18}$ F-FETNIM. ${ }^{18} \mathrm{~F}$-FETNIM is most useful for tumors of the head and neck, uterus, esophagus, and lung $(29,44)$. This radiopharmaceutical is considered hydrophilic, thus showing a low background signal. Its clearance is mainly renal and, partially, hepatobiliary $(20,24,38,44)$. 
${ }^{18}$ F-FAZA. Grönroos and Minn (44), Lopci et al. (20), Busk et al. (53,54), and Fleming et al. (29), encourage the use of ${ }^{18}$ F-FAZA, a second-generation nitroimidazole for head and neck tumors. Fleming et al. (29) also refer to its use in gliomas and in pulmonary, uterine, and colorectal tumors.

${ }^{18} \mathrm{~F}-\mathrm{FAZA}$ is a hydrophilic radiopharmaceutical with a LogP value of 0.04 and is characterized by high contrast between normoxic and hypoxic cells due to its extremely rapid clearance from normoxic cells $(4,24,29,50,54)$. Grégoire et al. (4) mention that some authors consider it a radiopharmaceutical of high chemical stability. It also is useful in detecting acute hypoxia (27).

Busk et al. (54) state that ${ }^{18} \mathrm{~F}$-FAZA had a relatively high SUV and demonstrated high intratumoral contrast.

According to Carlin and Humm (38), image acquisition is performed $3 \mathrm{~h}$ after radiopharmaceutical administration, whereas according to Peeters et al. (27), the ideal time for image acquisition is $2 \mathrm{~h}$ after administration.

${ }^{18} \mathrm{~F}$-HX4. ${ }^{18} \mathrm{~F}-\mathrm{HX} 4$ is most useful in tumors such as those of the head and neck, lung, and liver (29). It is one of the most sensitive radiopharmaceuticals for detection of acute hypoxia (27) and has the advantage of a relatively short time between administration and image acquisition (29). Clearance from organs such as the intestines and liver is relatively low, occurring mostly at the renal level, rapidly $(24,38,50)$.

${ }^{18} \mathrm{~F}-\mathrm{HX} 4$ contains 1,2,3-antitriazole, a hydrophilic molecule, and has a $\operatorname{LogP}$ of between -0.71 and $-0.67(24,29,50)$. It also contains 2-nitroimidazole and has a shorter biologic half-life in normoxic tissues than does ${ }^{18} \mathrm{~F}$-FMISO $(24,27,50)$.

For Peeters et al. (27) the ideal imaging time after administration is $3 \mathrm{~h}$, demonstrating a high tumor-to-background ratio. Hoeben et al. (18) consider $1.5 \mathrm{~h}$ the ideal time for obtaining images, whereas Fleming et al. (29) consider $4 \mathrm{~h}$ ideal.

${ }^{18} \mathrm{~F}-\mathrm{RP}-170 .{ }^{18} \mathrm{~F}-\mathrm{RP}-170$ is a useful radiopharmaceutical in tumors such as those of the brain and lung. Usefulness for detecting hypoxia in patients with gliomas has also been demonstrated $(24,29)$. This radiopharmaceutical exhibits higher SUVs for hypoxic than normal tissues, with greater contrast between tissues (24). However, because ${ }^{18} \mathrm{~F}-\mathrm{RP}-170$ is still under study as a radiopharmaceutical, not much information is yet available.

${ }^{18} \mathrm{~F}$-Pimonidazole $\left({ }^{18} \mathrm{~F}\right.$-FPIMO). ${ }^{18} \mathrm{~F}$-FPIMO is a 2-nitroimidazole radiopharmaceutical $(28,54)$ that uses the exogenous marker FPIMO (29). It is considered useful for identification of hypoxia because it has favorable chemical properties (55), namely the ability to bind to hypoxic cells in vivo, avoiding false-positive results (28).

Compared with ${ }^{18} \mathrm{~F}-\mathrm{FAZA},{ }^{18} \mathrm{~F}$-FPIMO has lower contrast between hypoxic and nonhypoxic cells; therefore, the SUV is also lower $(53,54)$. It was also shown that ${ }^{18} \mathrm{~F}$-FPIMO promotes the creation of circulating metabolites that are cleared via the hepatic and renal pathways $(53,54)$. This radiopharmaceutical is still being studied and, therefore, is not yet well characterized.

${ }^{18}$ F-EF5. EF5 was first investigated in nonradioactive form. Later, as a radiopharmaceutical, it was said to be a good indicator of regions of tumor hypoxia (55). ${ }^{18} \mathrm{~F}-\mathrm{EF} 5$, which contain 2-nitroimidazole, binds to hypoxic cells in vivo $(28,55) .{ }^{18} \mathrm{~F}-\mathrm{EF} 5$ easily passes through the cell membrane, as it is considered lipophilic $(20,24)$. The fact that this radiopharmaceutical accumulates in the same zones of hypoxia in PET images acquired at different times, and even on different days, makes ${ }^{18} \mathrm{~F}-\mathrm{EF} 5$ reproducible and viable (17). According to Komar et al. (56), for head and neck tumors, the ideal time from radiopharmaceutical administration to image acquisition is $3 \mathrm{~h}$.

${ }^{64} \mathrm{Cu}$-ATSM and ${ }^{62} \mathrm{Cu}$-ATSM. Other important radiopharmaceuticals for the detection of tumor hypoxia are ${ }^{64} \mathrm{Cu}$-ATSM and ${ }^{62} \mathrm{Cu}$-ATSM $(20,29,39-43,57)$. These are considered neutral and low-molecular-weight lipophilic molecules, meaning they are strongly able to permeate the cell membrane, and on entry into the cell, they are reduced to copper (I). Then, in the presence of hypoxic cells, they dissociate, which causes the copper ion to be allocated in the intracellular environment $(24,29,57)$.

Copper-ATSM is useful for tumors of the head and neck, lungs, kidneys, colon and rectum, bladder, and uterus (29). The second-generation ${ }^{64} \mathrm{Cu}$-ATSM analogs have high selectivity, providing better image quality due to their high absorption by hypoxic cells and rapid clearance from normoxic cells $(29,38,39,58,59)$. The lipophilicity of these radiopharmaceuticals is reduced, as is the waiting time for imaging (29). On the other hand, they have rapid diffusion; uptake occurs 1015 min after administration, which correlates with the short waiting time for image acquisition $(20,24)$. However, this radiopharmaceutical has reduced renal clearance and high hepatic accumulation, implying an increase in biologic halflife and, in turn, dosimetry for the patient $(39,58)$. The short half-life of ${ }^{62} \mathrm{Cu}$ requires a larger dose of radiation but also emits a low dose of radiation $(40,42-44)$.

Some authors use both ${ }^{62} \mathrm{Cu}$-ATSM and ${ }^{62} \mathrm{Cu}$-pyruvaldehyde-bis $\left(N^{4}\right.$-methylthiosemicarbazone), which has the potential to detect perfusion. Because of the short half-time, they can be used to acquire images before and after administration of the therapeutic, on the same day, and when they are used together, they can produce a more accurate map of hypoxia. This radiopharmaceutical clears rapidly from normal tissues, and image acquisition 10-15 min after injection has been used by some authors $(40-43)$.

\section{Systematic Analysis of Radiopharmaceuticals}

An analysis of these radiopharmaceuticals was performed (Table 2). A radiopharmaceutical with all the ideal characteristics has not yet been found (29). All except ${ }^{18} \mathrm{~F}-\mathrm{RP}-170$ and ${ }^{18} \mathrm{~F}$-FPIMO are sensitive in the evaluation of hypoxia in head and neck tumors $(23,29,35,44,48,56) .{ }^{18} \mathrm{~F}-\mathrm{FMISO}$ and ${ }^{64} \mathrm{Cu}-$ ATSM are approved by the Food and Drug Administration in the category of new drugs under investigation $(39,59,60)$.

${ }^{18} \mathrm{~F}-\mathrm{FMISO},{ }^{64} \mathrm{Cu}-\mathrm{ATSM}$, and ${ }^{18} \mathrm{~F}-\mathrm{EF} 5$ are lipophilic, and their entry into the cell is facilitated by passive diffusion through the cell membrane; thus, they have high retention in hypoxic cells. ${ }^{18} \mathrm{~F}$-FETNIM, ${ }^{18} \mathrm{~F}$-FAZA, and ${ }^{18} \mathrm{~F}$-HX4 4 are considered 


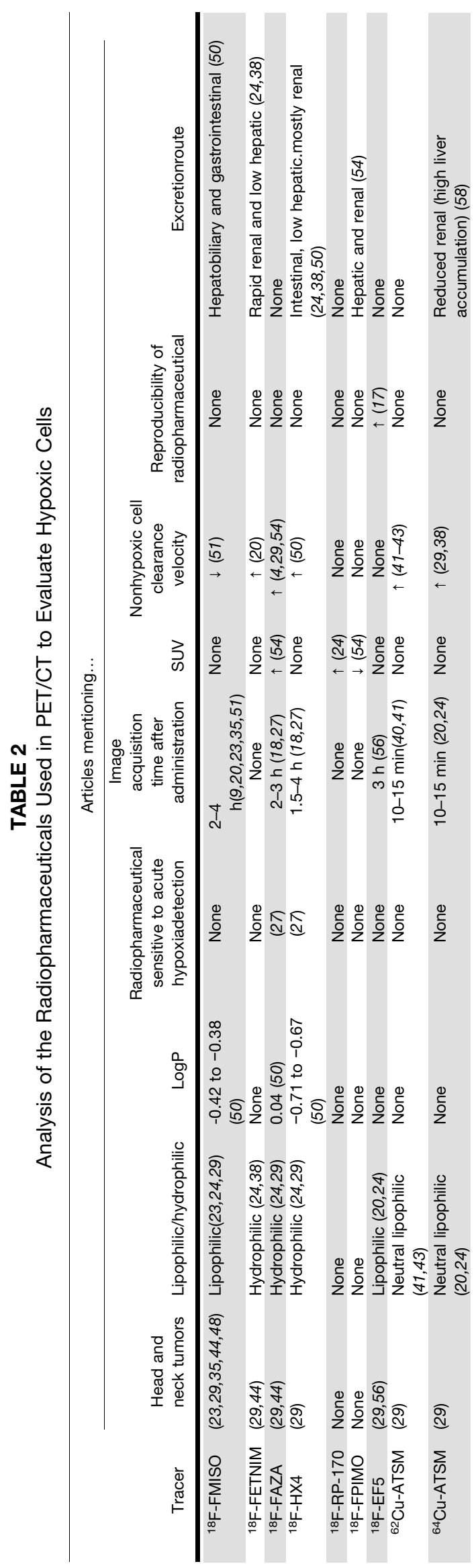

hydrophilic, as is evident from their rapid exit from normoxic cells. Both lipophilicity and hydrophilicity are important for increased radiopharmaceutical absorption and high contrast between hypoxic and nonhypoxic cells $(4,20,23,24,29,38)$. There are several authors who claim that ${ }^{18} \mathrm{~F}-\mathrm{FETNIM},{ }^{18} \mathrm{~F}-\mathrm{FAZA}$, and ${ }^{18} \mathrm{~F}-\mathrm{HX} 4$ are more hydrophilic than ${ }^{18} \mathrm{~F}$-FMISO $(20,29)$.

Compared with ${ }^{18} \mathrm{~F}$-FAZA, ${ }^{18} \mathrm{~F}-\mathrm{HX} 4$, and ${ }^{64} \mathrm{Cu}$-ATSM, ${ }^{18} \mathrm{~F}$ FMISO clears more slowly from normoxic cells and therefore produces less clear a distinction between hypoxic and nonhypoxic cells $(20,27,29,38,50,51,53,54)$. Compared with ${ }^{18} \mathrm{~F}$ FMISO, both ${ }^{18} \mathrm{~F}-\mathrm{HX} 4$ and ${ }^{18} \mathrm{~F}-\mathrm{FAZA}$ have a particular ability to detect acute cyclic or transient hypoxia after administration, as they are not influenced by reoxygenation. The fact that these radiopharmaceuticals can identify areas of acute hypoxia helps in choosing the most appropriate therapy (27).

In the Jakobsen et al. (54) study, when SUVs were compared between ${ }^{18} \mathrm{~F}$-FPIMO and ${ }^{18} \mathrm{~F}$-FAZA, the latter had relatively higher SUVs. ${ }^{18}$ F-FAZA therefore demonstrates higher uptake in hypoxic areas, leading to high intratumoral contrast. Biologic half-life in healthy tissues is lower for ${ }^{18} \mathrm{~F}-\mathrm{HX} 4$ and ${ }^{18} \mathrm{~F}$-FAZA than for ${ }^{18} \mathrm{~F}$-FMISO. Also, ${ }^{64} \mathrm{Cu}$-ATSM, ${ }^{62} \mathrm{Cu}-$ ATSM, and ${ }^{18}$ F-FETNIM have a short biologic half-life in normoxic tissues, implying that cell clearance in oxygenated tissues is higher $(20,27,29,39-43)$.

The excretion pathway of radiopharmaceuticals is also determined by their hydrophilicity or lipophilicity. Lipophilic drugs are eliminated mostly by the hepatobiliary route, whereas hydrophilic drugs are eliminated mostly by the renal route. Hepatobiliary excretion implies a higher dosimetry for the patient because clearance is slower. On the other hand, renal excretion is quick, thus implying a lower dosimetry for the patient. Excretion of ${ }^{18} \mathrm{~F}$-FMISO occurs via the hepatobiliary and gastrointestinal routes (50). Clearance of ${ }^{18} \mathrm{~F}$-FETNIM and ${ }^{18} \mathrm{~F}-\mathrm{HX} 4$ is mostly renal $(24,38,50) .{ }^{18} \mathrm{~F}$-FPIMO clearance is hepatic and renal (54). ${ }^{64} \mathrm{Cu}$-ATSM has a reduced renal clearance and marked hepatic absorption (58).

${ }^{18} \mathrm{~F}-\mathrm{EF} 5$ has high reproducibility, which provides consistent image results from consecutively acquired PET scans (17).

\section{PET/CT in Radiotherapy Planning}

PET images can identify areas of disease not easily visible on CT for therapy planning, as PET can identify molecular changes $(7,48,61)$. Molecular imaging is useful for visualizing the primary tumor, ganglion involvement, and metastatic disease $(62,63)$.

Hybrid imaging for radiotherapy planning gives greater sensitivity and precision in delimiting lesions, enabling a change in therapeutic approach in $10 \%-30 \%$ of patients as compared to other reference imaging modalities and providing an individualized and rigorous treatment that reduces the likelihood of side effects. Hybrid imaging also allows construction of an accurate map of hypoxia zones for individual patients $(6,7,11,29,35,61,63-65)$.

The main purpose of radiotherapy is to potentiate the dose at the target volume without compromising healthy tissues. For this purpose, delimitation of the target volume and organs 
at risk must be precise, and the tolerance dose to the organs at risk should not be exceeded $(7,9,11,12,61,63)$. PET/CT is a promising tool in treatment planning for head and neck tumors, particularly with the application of IMRT or VMATtwo noninvasive treatments useful in small, irregular volumes within a target volume because they can effectively distribute the radiation dose and match the volume of interest defined on PET/CT $(44,66)$.

\section{Advantages of PET/CT Planning for Treatment of Head and Neck Tumors}

In a study by Johansen et al. (16), most relapses occurred in locoregional lymph nodes for reasons such as insufficient total dose, primary tumor histologic type, an inaccurate therapy-planning image, and inadequate target volume delimitation. Such reasons may also contribute to relapses after the use of highly conformal therapies by increasing the likelihood of marginal failure $(6,16,67)$.

Because head and neck tumors are sensitive to oxygen levels during radiotherapy (17), planning radiotherapy through PET/ CT imaging of hypoxia is useful for subsequent application of IMRT/VMAT, especially if it is possible to use radiopharmaceuticals that allow good intrinsic resolution and 3-dimensional representations, allowing deposition of a larger dose in radioresistant volumes. PET/CT planning and IMRT/VMAT for treatment are also relevant because a lower dose to the organs at risk is intended, reducing the likelihood of xerostomia and other treatment-related toxicities and increasing the probability of tumor control $(8,9,20,24,29,33,35,52,66)$.

PET/CT planning and treatment techniques are suitable for head and neck tumors, as these cancers are near at-risk organs with irregular contours. This difficulty is overcome by the detection and evaluation of tumor hypoxia, a capability that plays an important role in achieving greater locoregional control by decreasing the risk of recurrence $(8,9,16,22,47,48)$.

\section{DISCUSSION}

Tumor hypoxia contributes to a poor prognosis. In radiotherapy, the presence of oxygen in a tumor enhances the biologic effect that leads to tumor-cell destruction, whereas hypoxia inhibits the biologic effect and increases resistance $(22,28,30,32)$. The low oxygenation rate in regions of hypoxic cells requires a 3 -fold increase in radiation dose so as to obtain results similar to those in well-oxygenated areas (8).

The use of PET/CT to plan radiotherapy for head and neck tumors better defines regions of lower cellular oxygenation. With the information from PET/CT, the irradiation can focused to subvolume levels to counteract resistance $(4,29,65)$. As compared with other image techniques that are used to plan therapy, molecular imaging leads to a change in the therapeutic approach and thus an increase in efficacy and a decrease in intraobserver and interobserver variability $(7,61,62)$.

The radiopharmaceuticals used to detect tumor hypoxia include ${ }^{18} \mathrm{~F}$-FMISO, ${ }^{18} \mathrm{~F}$-FETNIM, ${ }^{18} \mathrm{~F}$-FAZA, ${ }^{18} \mathrm{~F}$-HX4, ${ }^{18} \mathrm{~F}$ RP-170, ${ }^{18}$ F-FPIMO, ${ }^{18} \mathrm{~F}-\mathrm{EF} 5,{ }^{62} \mathrm{Cu}-\mathrm{ATSM}$, and ${ }^{64} \mathrm{Cu}$-ATSM
$(17,29,33,35,40-42,50,54,55,57,58)$. However, these have limitations, as none exhibits entirely ideal properties and all are still under investigation (29). According to Kelada and Carlson (19) and Komar et al. (56), ${ }^{18}$ F-EF5 is promising but needs further clinical studies. Another promising candidate is ${ }^{18}$ F-FAZA, because of its high hydrophilicity, high affinity for hypoxia, high tumor-to-background contrast, and ability to detect acute hypoxia.

PET/CT increases the accuracy of planning the target volume and delimiting the organs at risk. IMRT and VMAT allow for a highly conformal dose to the volume to be treated, in order to decrease the dose to organs at risk and increase the probability of tumor control $(4,6,35,67)$.

\section{CONCLUSION}

The validity of using PET/CT to plan radiotherapy and subsequent IMRT/VMAT of hypoxic tumors remains under study because some information is still needed, including the importance and real clinical efficacy of this planning technique in the follow-up of cancer patients (28). Future studies need to establish a PET/CT protocol for evaluating areas of acute and chronic hypoxia and clarify the side effects of hypoxia-directed radiotherapy.

\section{DISCLOSURE}

No potential conflict of interest relevant to this article was reported.

\section{REFERENCES}

1. Munshi N. Imaging evolution: hybrid PET/CT scans. Imaging Technology News website. https://www.itnonline.com/article/imaging-evolution-hybrid-petct-scans. Published May 3, 2012. Accessed January 6, 2021.

2. Czernin J, Schelbert H. PET/CT imaging: facts, opinions, hopes, and questions. J Nucl Med. 2004;45(suppl):1S-3S.

3. Kinggaard Federspiel M, Hogg P, eds. PET/CT Radiotherapy Planning: A Technologist Guide. European Association of Nuclear Medicine; 2012:4, 5, 34, 35, 36, 41, 42, 63, 64, 65, 74-78.

4. Grégoire V, Thorwarth D, Lee JA. Molecular imaging-guided radiotherapy for the treatment of head-and-neck squamous cell carcinoma: does it fulfill the promises? Semin Radiat Oncol. 2018;28:35-45.

5. Kapoor V, McCook BM, Torok FS. An introduction to PET-CT imaging. Radiographics. 2004;24:523-543.

6. Vanderstraeten B, Duthoy W, De Gersem W, De Neve W, Thierens H. $\left[{ }^{18}\right.$ F fluorodeoxy-glucose positron emission tomography [ $\left.{ }^{18} \mathrm{~F}\right] \mathrm{FDG}$-PET voxel intensity-based intensity-modulated radiation therapy (IMRT) for head and neck cancer. Radiother Oncol. 2006;79:249-258.

7. Gupta T, Beriwal S. PET/CT-guided radiation therapy planning: from present to the future. Indian J Cancer. 2010;47:126-133.

8. Hendrickson K, Phillips M, Smith W, Peterson L, Krohn K, Rajendran J. Hypoxia imaging with [F-18] FMISO-PET in head and neck cancer: potential for guiding intensity modulated radiation therapy in overcoming hypoxia-induced treatment resistance. Radiother Oncol. 2011;101:369-375.

9. Lee NY, Mechalakos JG, Nehmeh S, et al. Fluorine-18-labeled fluoromisonidazole positron emission and computed tomography-guided intensity-modulated radiotherapy for head and neck cancer: a feasibility study. Int J Radiat Oncol Biol Phys. 2008;70:2-13.

10. Welsh L, Panek R, McQuaid D, et al. Prospective, longitudinal, multi-modal functional imaging for radical chemo-IMRT treatment of locally advanced head and neck cancer: the INSIGHT study. Radiat Oncol. 2015;10:112.

11. Delikgoz Soykut E, Ozsahin EM, Yukselen Guney Y et al. The use of PET/CT in radiotherapy planning: contribution of deformable registration. Front Oncol. 2013;3:33. 
12. Ceylan Y, Omur O, Hatipoglu F. Contribution of ${ }^{18} \mathrm{~F}-\mathrm{FDG}$ PET/CT to staging of head and neck malignancies. Mol Imaging Radionucl Ther. 2018;27:19-24.

13. Head and neck cancers. SNMMI website. http://www.snmmi.org/AboutSNMMI/ Content.aspx?ItemNumber=947. Accessed January 6, 2021.

14. Registo oncológico nacional 2010. Ipoporto website. https://www.ipoporto.pt/ dev/wp-content/uploads/2013/03/ro_nacional_2010.pdf. Published April 2016. Accessed January 6, 2021.

15. Estêvão R, Santos T, Ferreira A, Machado A, Fernandes J, Monteiro E. Epidemiological and demographic characteristics of patients with head and neck tumours in the northern Portugal: impact on survival [in Portuguese]. Acta Med Port. 2016;29:597-604.

16. Johansen S, Norman MH, Dale E, et al. Patterns of local-regional recurrence after conformal and intensity-modulated radiotherapy for head and neck cancer. Radiat Oncol. 2017;12:87.

17. Silvoniemi A, Suilamo S, Laitinen T, et al. Repeatability of tumour hypoxia imaging using $\left[{ }^{18} \mathrm{~F}\right] \mathrm{EF} 5 \mathrm{PET} / \mathrm{CT}$ in head and neck cancer. Eur J Nucl Med Mol Imaging. 2018;45:161-169.

18. Hoeben BA, Bussink J, Troost EG, Oyen WJ, Kaanders JH. Molecular PET imaging for biology-guided adaptive radiotherapy of head and neck cancer. Acta Oncol. 2013;52:1257-1271.

19. Kelada OJ, Carlson DJ. Molecular imaging of tumor hypoxia with positron emission tomography. Radiat Res. 2014;181:335-349.

20. Lopci E, Grassi I, Chiti A et al. PET radiopharmaceuticals for imaging of tumor hypoxia: a review of the evidence. Am J Nucl Med Mol Imaging. 2014;4:365384.

21. Matsumoto S, Yasui H, Mitchell JB, Krishna MC. Imaging cycling tumor hypoxia. Cancer Res. 2010;70:10019-10023.

22. Walsh JC, Lebedev A, Aten E, Madsen K, Marciano L, Kolb HC. The clinical importance of assessing tumor hypoxia: relationship of tumor hypoxia to prognosis and therapeutic opportunities. Antioxid Redox Signal. 2014;21:1516-1554.

23. Lapa P, Jacobetty M, Teixeira T, et al. Evaluation of tumor hypoxia by PET/CT with fluoromisonidazole $\left({ }^{18} \mathrm{~F}\right)$ when planning radiotherapy: initial experience [in Portuguese]. Acta Radiológica Portuguesa. 2015;27:59-65.

24. Challapalli A, Carroll L, Aboagye EO. Molecular mechanisms of hypoxia in cancer. Clin Transl Imaging. 2017;5:225-253.

25. Eales KL, Hollinshead KE, Tennant DA. Hypoxia and metabolic adaptation of cancer cells. Oncogenesis. 2016;5:e190.

26. Muz B, de la Puente P, Azab F, Azab AK. The role of hypoxia in cancer progression, angiogenesis, metastasis, and resistance to therapy. Hypoxia (Auckl). 2015;3:83-92.

27. Peeters SGJA, Zegers CML, Lieuwes NG, et al. A comparative study of the hypoxia PET tracers [F-18]HX4, [F-18]FAZA, and [F-18]FMISO in a preclinical tumor model. Int J Radiat Oncol Biol Phys. 2015;91:351-359.

28. Rademakers SE, Span PN, Kaanders JH, Sweep FC, van der Kogel AJ, Bussink J. Molecular aspects of tumour hypoxia. Mol Oncol. 2008;2:41-53.

29. Fleming IN, Manavaki R, Blower PJ, et al. Imaging tumour hypoxia with positron emission tomography. Br J Cancer. 2015;112:238-250.

30. Okamoto S, Shiga T, Yasuda K, et al. High reproducibility of tumor hypoxia evaluated by ${ }^{18} \mathrm{~F}$-fluoromisonidazole PET for head and neck cancer. $\mathrm{J}$ Nucl Med. 2013;54:201-207.

31. Cárdenas-Navia LI, Mace D, Richardson RA, Wilson DF, Shan S, Dewhirst MW. The pervasive presence of fluctuating oxygenation in tumors. Cancer Res. 2008;68:5812-5819.

32. Radiation Oncology Physics: A Handbook for Teachers and Students. International Atomic Energy Agency; 2005:32, 488, 489, 498, 499, 545-547.

33. Thorwarth D, Welz S, Mönnich D, et al. Prospective evaluation of a tumor control probability model based on dynamic ${ }^{18} \mathrm{~F}-\mathrm{FMISO}$ PET for head and neck cancer radiotherapy. J Nucl Med. 2019;60:1698-1704.

34. Betts HM, O'Connor RA, Christian JA, et al. Hypoxia imaging with $\left[{ }^{18} \mathrm{~F}\right] \mathrm{HX} 4$ PET in squamous cell head and neck cancers: a pilot study for integration into treatment planning. Nucl Med Commun. 2019;40:73-78.

35. Chang JH, Wada M, Anderson NJ, et al. Hypoxia-targeted radiotherapy dose painting for head and neck cancer using ${ }^{18} \mathrm{~F}$-FMISO PET: a biological modeling study. Acta Oncol. 2013;52:1723-1729.

36. Jacobson O, Kiesewetter DO, Chen X. Fluorine-18 radiochemistry, labeling strategies and synthetic routes. Bioconjug Chem. 2015;26:1-18.

37. Salem A, Asselin MC, Reymen B, et al. Targeting hypoxia to improve non-small cell lung cancer outcome. J Natl Cancer Inst. 2018;110(1).

38. Carlin S, Humm JL. PET of hypoxia: current and future perspectives. $J$ Nucl Med. 2012;53:1171-1174.

39. Anderson CJ, Ferdani R. Copper-64 radiopharmaceuticals for PET imaging of cancer: advances in preclinical and clinical research. Cancer Biother Radiopharm. 2009;24:379-393.

40. Wong TZ, Lacy JL, Petry NA, et al. PET of hypoxia and perfusion with ${ }^{62} \mathrm{Cu}-$ ATSM and ${ }^{62} \mathrm{Cu}-\mathrm{PTSM}$ using a ${ }^{62} \mathrm{Zn} /{ }^{62} \mathrm{Cu}$ generator. AJR. 2008;190:427-432.
41. Fujibayashi Y, Taniuchi H, Yonekura Y, Ohtani H, Konishi J, Yokoyama A. Copper-62-ATSM: a new hypoxia imaging agent with high membrane permeability and low redox potential. J Nucl Med. 1997;38:1155-1160.

42. Zhang T, Das SK, Fels DR, et al. PET with ${ }^{62} \mathrm{Cu}-\mathrm{ATSM}$ and ${ }^{62} \mathrm{Cu}-\mathrm{PTSM}$ is a useful imaging tool for hypoxia and perfusion in pulmonary lesions. AJR. 2013;201:W698-W706.

43. Lapi SE, Lewis JS, Dehdashti F. Evaluation of hypoxia with copper-labeled diacetyl-bis(N-methylthiosemicarbazone). Semin Nucl Med. 2015;45:177-185.

44. Grönroos T, Minn H. Imaging of tumour hypoxia using PET and ${ }^{18} \mathrm{~F}$-labelled tracers: biology meets technology. Eur J Nucl Med Mol Imaging. 2007;34:1563-1565.

45. Yu W, Qiao F, Su X, et al. ${ }^{18} \mathrm{~F}-\mathrm{HX} 4 /{ }^{18} \mathrm{~F}$-FMISO-based micro PET for imaging of tumor hypoxia and radiotherapy-associated changes in mice. Biomed Pharmacother. 2019;119:109454.

46. Duncan D. Use of radionuclides in imaging and therapy. In: Cherry P, Duxbury A, eds. Practical Radiotherapy: Physics and Equipment. 2nd ed. Wiley-Blackwell; 2009:239-256.

47. Nehmeh SA, Lee NY, Schroder H, et al. Reproducibility of intratumor distribution of ${ }^{18} \mathrm{~F}$-fluoromisonidazole in head and neck cancer. Int J Radiat Oncol Biol Phys. 2008;70:235-242.

48. Ferrer Albiach C, Conde Moreno A, Rodriguez Cordon M, et al. Contribution of hypoxia-measuring molecular imaging techniques to radiotherapy planning and treatment. Clin Transl Oncol. 2010;12:22-26.

49. Grkovski M, Schoder H, Lee NY, et al. Multiparametric imaging of tumor hypoxia and perfusion with ${ }^{18} \mathrm{~F}$-fluoromisonidazole dynamic PET in head and neck cancer. J Nucl Med. 2017;58:1072-1080.

50. Dubois LJ, Lieuwes NG, Janssen MHM, et al. Preclinical evaluation and validation of [F-18]HX4, a promising hypoxia marker for PET imaging. Proc Natl Acad Sci USA. 2011;108:14620-14625.

51. Choi W, Lee SW, Park SH, et al. Planning study for available dose of hypoxic tumor volume using fluorine-18-labeled fluoromisonidazole positron emission tomography for treatment of the head and neck cancer. Radiother Oncol. 2010;97:176-182.

52. Lin Z, Mechalakos J, Nehmeh S, et al. The influence of changes in tumor hypoxia on dose-painting treatment plans based on ${ }^{18} \mathrm{~F}$-FMISO positron emission tomography. Int J Radiat Oncol Biol Phys. 2008;70:1219-1228.

53. Busk M, Mortensen LS, Nordsmark M, et al. PET hypoxia imaging with FAZA: reproducibility at baseline and during fractionated radiotherapy in tumour-bearing mice. Eur J Nucl Med Mol Imaging. 2013;40:186-197.

54. Busk M, Jakobsen S, Horsman MR, et al. PET imaging of tumor hypoxia using ${ }^{18}$ F-labeled pimonidazole. Acta Oncol. 2013;52:1300-1307.

55. Chitneni SK, Bida GT, Yuan H, et al. ${ }^{18} \mathrm{~F}$-EF5 PET imaging as an early response biomarker for the hypoxia-activated prodrug SN30000 combined with radiation treatment in a non-small cell lung cancer xenograft model. J Nucl Med. 2013;54:1339-1346.

56. Komar G, Seppanen M, Eskola O, et al. ${ }^{18}$ F-EF5: a new PET tracer for imaging hypoxia in head and neck cancer. J Nucl Med. 2008;49:1944-1951.

57. Hueting R, Kersemans V, Cornelissen B, et al. A comparison of the behavior of ${ }^{64} \mathrm{Cu}$-acetate and ${ }^{64} \mathrm{Cu}$-ATSM in vitro and in vivo. J Nucl Med. 2014;55:128-134.

58. Carlin S, Zhang H, Reese M, Ramos NN, Chen Q, Ricketts SA. A comparison of the imaging characteristics and microregional distribution of 4 hypoxia PET tracers. J Nucl Med. 2014;55:515-521.

59. FMISO documentation page. National Cancer Institute website. https://imagingcancer. gov/programs_resources/cancer-tracer-synthesis-resources/FMISO_documentation. htm. Updated August 6, 2019. Accessed January 6, 2021.

60. IND regulatory \& manufacturing resources. National Cancer Institute website. https://imaging.cancer.gov/programs_resources/IND_regulatory_manufacturing.htm. Updated February 27, 2020. Accessed January 6, 2021.

61. Sattler B, Lee JA, Lonsdale M, Coche E. PET/CT (and CT) instrumentation, image reconstruction and data transfer for radiotherapy planning. Radiother Oncol. 2010;96:288-297.

62. PET/CT planning beneficial for head and neck cancer patients. News-Medical.Net website. http://www.news-medical.net/news/2008/03/06/35993.aspx\#. Published March 6, 2008. Accessed January 6, 2021.

63. Gregoire V, Chiti A. PET in radiotherapy planning: particularly exquisite test or pending and experimental tool? Radiother Oncol. 2010;96:275-276.

64. The Role of PET/CT in Radiation Treatment Planning for Cancer Patient Treatment. IAEA; 2008. AEA-TECDOC-1603.

65. Parodi K. Vision 20/20: Positron emission tomography in radiation therapy planning, delivery, and monitoring. Med Phys. 2015;42:7153-7168.

66. Prescribing, recording, and reporting photon-beam intensity-modulated radiation therapy (IMRT): contents. J ICRU. 2010;10:NP.

67. Chakraborty S, Patil VM, Babu S, Muttath G, Thiagarajan SK. Locoregional recurrences after post-operative volumetric modulated arc radiotherapy (VMAT) in oral cavity cancers in a resource constrained setting: experience and lessons learned. Br J Radiol. 2015;88:20140795. 